\title{
Kontribusi Kemampuan Daya Ledak Otot Tungkai Terhadap Kecepatan Renang 50 Meter Gaya Dada Atlet Renang Kota Padang
}

\author{
Naluri Denay \\ Fakultas Ilmu Keolahragaan, Universitas Negeri Padang, Indonesia. \\ E-mail:naluri@unp.ac.id. ${ }^{1}$
}

\begin{abstract}
Abstrak
Penelitian ini berawal dari prestasi renang Sumatera Barat yang diwakili Kota Padang akhirakhir ini mengalami kemunduran. Penelitian ini bertujuan untuk mengetahui tentang Kontribusi daya ledak otot tungkai terhadap kecepatan renang 50 meter gaya dada atlet renang Kota Padang. Berdasarkan kajian teori, maka dapat diajukan hipotesis penelitian sebagai berikut: "terdapat kontribusi yang berarti antara daya ledak otot tungkai dengan kecepatan renang 50 meter gaya dada".Jenis penelitian ini adalah korelasional dengan populasi atlet-atlet putra pada perkumpulan renang di Kota Padang dan sampel diambil dengan menggunakan teknik samplingjenuh sebanyak 16 orang. Teknik pengambilan data dilakukan dengan cara mengukur berat badan dengan timbangan, daya ledak otot tungkai dengan verticaljump menggunakan Nomogram Lewis dan tes kecepatan renang 50 meter gaya dada dengan stopwatch. Analisa data dan pengujian hipotesis penulisan menggunakan teknik analisis korelasi sederhana dengan taraf signifikan $\alpha=0,05$. Dari analisis data dapat diperoleh hasil : Terdapat Kontribusi Antara Daya Ledak Otot Tungkai Terhadap Kecepatan Renang 50 Meter Gaya Dada Atlet Renang Kota Padang sebesar 53,9 \%.
\end{abstract}

Kata Kunci: Daya ledak otot tungkai dan kecepatan renang 50 meter gaya dada.

\begin{abstract}
This research begins with the swimming achievements of West Sumatra, represented by the city of Padang, which recently declined. This study aims to find out about the contribution of leg muscle explosive power to the swimming speed of the 50 meter breaststroke athlete in the city of Padang. Based on a theoretical study, it can be proposed the following research hypothesis: "there is a significant contribution between the leg muscle explosive power and swimming speed of 50 meters breaststroke". This type of research is correlational with the population of male athletes in swimming clubs in the city of Padang and samples taken using 16 saturated sampling techniques. Data collection techniques were carried out by measuring body weight with scales, leg muscle explosive power with vertical jump using Nomogram Lewis and a 50 meter breaststroke swimming speed test with a stopwatch. Data analysis and hypothesis testing using simple correlation analysis techniques with a significant level $\alpha=0.05$. From the analysis of the data it can be obtained the results: There is a Contribution Between the Explosion Power of the Leg Muscles to the Swimming Speed of the 50meter Chest Force of the Swimming Athlete in Padang by 53.9\%.
\end{abstract}

Keywords:The explosive power of the leg muscles and swimming speed of 50 meters breaststroke.

\section{PENDAHULUAN}

Renang merupakan salah satu cabang olahraga dari sekian banyak cabang olahraga yang sudah maju dan berkembang. Hal ini dapat dibuktikan dari sarana dan prasarana yang memadai, organisasi yang baik dan banyaknya perkumpulan renang yang melakukan pembinaan. Selain itu, juga ramainya kolam renang dikunjungi oleh semua lapisan masyarakat.

Seiring dengan hal di atas, sudah sepatutnyalah prestasi olahraga renang semakin meningkat, khususnya di Kota Padang. Kita juga sering melihat adanya perlombaan baik tingkat pelajar, daerah maupun sampai tingkat nasional. Adapun gaya renang yang diperlombakan dalam kejuaraan renang 
terdiri dari empat gaya yaitu "Gaya Bebas, Gaya Kupu-kupu, Gaya Punggung, Gaya Dada", Depdikbud (1982). Keempat gaya yang diperlombakan tersebut masing-masing memiliki dan membutuhkan komponen fisik yang berbeda. Namun, pada prinsipnya sama yaitu berusaha untuk berenang secepat mungkin mulai dari start sampai finish.

Upaya pencapaian prestasi puncak dalam cabang olahraga renang di Kota Padang sangat banyak faktor yang mempengaruhi, menurut Syafrudin (1999) diantaranya: "kemampuan fisiknya, teknik, taktik dan mental. Ken dalam Arsil (1999) menjelaskan "kecepatan bergerak ditentukan oleh faktor kekuatan otot, daya ledak, daya koordinasi gerakan, kelincahan, dan keseimbangan".

Berdasarkan pemikiran dari permasalahan diatas, diduga daya ledak otot tungkai perenang sangat berperan memberi kontribusi terhadap kecepatan renang 50 meter gaya dada. Oleh sebab itu peneliti tertarik untuk melakukan penelitian ini.

Adapun tujuan penelitian ini adalah "untuk mengetahui seberapa besar kontribusi kemampuan daya ledak otot tungkai terhadap kecepatan renang 50 meter gaya dada atlet renang Kota Padang"

\section{METODE}

Jenis penelitian ini adalah penelitian korelasional, yang bertujuan untuk mengetahui dan menyelidiki sejauh mana kontribusi dan peranan variabel-variabel prediktor terhadap variabel yang diprediksi berdasarkan koefisien korelasi. Sesuai pendapat Umar (1998) penelitian korelasional adalah suatu penelitian yang dirancang untuk menentukan tingkat kontribusi variabel-variabel dalam suatu populasi, yang bertujuan untuk mengetahui seberapa besar kontribusi variabel bebas terhadap variabel terikat serta besarnya kaitan yang terjadi. Dalam penelitian ini variabel bebasnya adalah daya ledak otot tungkai (x), sedangkan variabel yang diprediksi atau variabel terikatnya adalah kecepatan renang 50 meter gaya dada (y). Penelitian ini dilaksanakan di kolam renang Teratai GOR H. Agus Salim Padang. Waktu pengambilan data penelitian dilakukan pada tanggal 28 Juli-10 Agustus 2010.

Populasi merupakan totalitas semua nilai yang mungkin daripada karakteristik tertentu sejumlah objek yang ingin dipelajari sifat-sifatnya (Yusuf 2007). Populasi penelitian ini adalah atletatlet putra perkumpulan renang Kota Padang. Yang dimaksud atlet renang Kota Padang adalah para olahragawan yang berlatih cabang olahraga renang dan berdomisili di Kota Padang untuk meningkatkan prestasi dalam persiapan menghadapi kegiatan kejuaraan renang. Para perenang diantaranya telah mengikuti seleksi ataupun kejuaraan renang seperti O2SN tingkat SMP se Kota Padang, se Sumatera Barat, dan Nasional, serta para atlet yang pernah mengikuti Pekan Olahraga Pelajar tingkat Kota Padang, Sumatera Barat, dan Nasional. Kemudian yang pernah mengikuti kujuaraan renang antar perkumpulan se Sumetera dan se Indonesia, dan juga Pekan Olahraga Wilayah se Sumatera.

\begin{tabular}{llc}
\multicolumn{3}{c}{ Tabel 1: Jumlah populasi atlet renang Kota Padang } \\
\hline No & Nama Club & Jumlah Atlet (orang) \\
\hline 1 & Alfret & 3 \\
2 & Ambacang & 2 \\
3 & Profi & 3 \\
4 & Tirta Kaluang & 4 \\
5 & Pesut & 1 \\
6 & Women Swimming Club & 3 \\
7 & Lumba-Lumba & 0 \\
& Jumlah & 16 \\
\hline
\end{tabular}

Sampel adalah sebagian dari populasi yang terpilih dan mewakili populasi tersebut (Yusuf 2007), karena keterbatasan populasi, maka sampel yang di ambil menggunakan teknik sampling jenuh, yaitu teknik pengambilan sampel apabila semua populasi digunakan sebagai sampel dan dikenal sebagai istilah sensus. Samplingjenuh dilakukan bila populasinya kurang dari 30 orang, Riduwan (2004). 


\begin{tabular}{llll} 
& \multicolumn{3}{l}{ Tabel 2: Jumlah sampel penelitian } \\
\hline No & $\begin{array}{l}\text { Populasi } \\
\text { (orang) }\end{array}$ & $\begin{array}{l}\text { Sampel } \\
\text { (orang) }\end{array}$ & $\begin{array}{l}\text { Jumlah } \\
\text { (orang) }\end{array}$ \\
\hline 1 & 16 & 16 & 16 \\
\hline
\end{tabular}

Jenis data penelitian yang diambil dalam suatu penelitian yaitu: data primer (data yang diambil langsung melalui tes daya ledak otot tungkai dan tes kecepatan renang 50 meter daya dada) dan data sekunder (data atlet yang diambil dari hasil dokumentasi).

Sumber Data. Data yang diperoleh dalam penelitian ini diambil langsung dari tes yang dilakukan terhadap Atlet renang Kota Padang yang masih aktif latihan pada Tahun 2010.

\section{Teknik Pengumpulan Data}

Teknik pengumpulan data dalam penelitian ini adalah tes untuk mengukur daya ledak otot tungkai menurut Lutan (1991) dengan Vertical Jump dan tes kecepatan renang 50 meter gaya dada dengan alat ukur stopwatch.

Instrumen Penelitian dan Pelaksanaan Tes kerja yaitu :

Untuk mendapatkan data dalam penelitian ini terlebih dahulu membuat beberapa laangkah

1. Mendapatkan surat izin untuk melakukan penelitian

2. Menyiapkan tim yang terlibat di dalam pengumpulan data.

Tabel 3. Petugas pelaksana dalam penelitian

\begin{tabular}{|l|l|l|}
\hline No & Nama & Tugas \\
\hline 1. & Rico Candra Negoro & Pencatat skor \\
\hline 2. & Widodo & Timer \\
\hline 3. & Anugrah Muhardi & Dokumentasi \\
\hline 4. & Naluri Denay & Starter \\
\hline
\end{tabular}

3. Menyiapkan alat-alat perlengkapan untuk pengambilan data

4. Mengambil data langsung pada sampel.

Untuk mengumpulkan data penelitian, peneliti menggunakan instrument test untuk masingmasing variabelseperti berikut:

1. Tes daya ledak otot tungkai (Vertical Jump)

a. Tujuan : Tes ini bertujuan untuk mengukur daya ledak otot tungkai/tenaga eksplosif dan teknik yang dipakai yaitu Nomogram Lewis.

b. Alat : Meteran

Timbangan

Pena

Kertas

Kapur

Papan skor

c. Pelaksanaan tes

1. Pertama testee di timbang berat badannya terlebih dahulu

2. Pada suata dinding yang lurus dari lantai dipasang papan skor setinggi $300 \mathrm{~cm}$.

3. Testee berdiri di dekat dinding dan di ukur raihannya pada ukuran papan skor.

4. Selanjutnya testee melompat untuk meraih tinggi jangkauannya.

5. Hitung selisih tinggi raihan antara antara raihan berdiri dengan jangkauan melompat pada papan. 
6. Olah hasil raihan dengan berat badan menggunakan rumus Nomogram Lewis :

$$
\begin{aligned}
& \mathrm{P}=\sqrt{4.9} \text { (weight). } \sqrt{D^{*}} \\
& \mathrm{P} \quad=\text { daya ledak } \\
& \text { Weight }=\text { berat badan } \\
& D^{*} \quad=\text { selisih raihan dan lompatan }
\end{aligned}
$$

Tabel 4 :kategori daya ledak otot tungkai dengan vertical jump

\begin{tabular}{ll}
\hline kategori & Putra \\
\hline Baik Sekali & $>301$ \\
Baik & $240-300$ \\
Cukup & $115-230$ \\
Kurang & $54-114$ \\
Kurang sekali & $0-53$ \\
\hline
\end{tabular}

Sumber : pusat kesegaran jasmani dan rekreasi, depdikbud, 1996

2. Tes kecepatan renang 50 meter gaya dada

Tes kecepatan renang 50 meter gaya dada sesuai dengan peraturan PRSI diukur dalam satuan waktu detik dua angka dibelakang koma.

\section{Teknik Analisis Data}

Sebelum dilakukan uji hipotesis dilakukan uji persyaratan analisis data dengan uji normalitas data (uji liliefors) pada signifikan 0,05. Kemudian setelah itu dikarenakan alat tes yang berbeda menyebabkan jumlah digit angka pada data pun berbeda sehingga haruslah dirubah kedalam bentuk $T$ Score dengan menggunakan formulaT-Score dari Don R Kirkendall (1980) yaitu dengan rumus sebagai berikut :

$\mathrm{x}=$ Angka mentah

$$
T \text {-Score }=50 \pm 10\left(\frac{x-\bar{x}}{S d}\right)
$$

$\bar{x}=$ Angka rata-rata

$\mathrm{Sd}=$ Standar deviasi

Selanjutnya untuk memperoleh gambaran tentang karakteristik dari masing-masing variabel penelitian digunakan analisis statistik deskriptif dan distribusi frekuensi yang disajikan dalam bentuk tabel. sebagai berikut :

Berdasarkan pada hipotesis yang diajukan, analisis data yang dilakukan dapat dikemukakan

Hipotesis diuji dengan menggunakan rumus korelasi product moment dan rumus kontribusi oleh Pearson dalam Sudjana (1992):

$$
r_{x y}=\frac{\mathrm{n} \sum \mathrm{xy}-\left(\sum \mathrm{x}\right)\left(\sum \mathrm{y}\right)}{\sqrt{\left\{\mathrm{n} \sum \mathrm{x}^{2}-\left(\sum \mathrm{x}\right)^{2}\right\}}\left\{\mathrm{n} \sum \mathrm{y}^{2}-\left(\sum \mathrm{y}\right)^{2}\right\}}
$$

$$
\begin{aligned}
\text { Ket }: r_{x y} & =\text { Koefisien korelasi product moment } \\
\mathrm{x} & =\text { Hasil tes kekuatan otot tungkai } \\
\mathrm{y} & =\text { Angka tes kemampuan kecepatan renang } \\
\mathrm{n} & =\text { Jumlah sampel }
\end{aligned}
$$

untuk melihat besarnya kontribusi melalui indeks determinasi yaitu:

$$
r^{2} \times 100 \%
$$




\section{HASIL DAN PEMBAHASAN \\ Hasil Penelitian}

\section{Daya ledak otot tungkai (x)}

Pengukuran daya ledak otot tungkai dilakukan dengan tes vertical jump terhadap 16 orang sampel, didapat skor tertinggi 120, skor terendah 51, rata-rata (mean) 88.31, standar deviasi 22.93 . untuk lebih jelasnya lihat pada tabel berikut:

\begin{tabular}{|c|c|c|}
\hline No & Kelas interval & $\begin{array}{l}\text { Frekuensi } \\
\text { Absolute }(\mathrm{Fa})\end{array}$ \\
\hline 1 & $>301$ & 0 \\
\hline 2 & $240-300$ & 0 \\
\hline 3 & $115-230$ & 2 \\
\hline 4 & $54-114$ & 13 \\
\hline \multirow[t]{4}{*}{5} & $0-53$ & 1 \\
\hline & Jumlah & 16 \\
\hline & mean & 88.31 \\
\hline & stdv & 22.93 \\
\hline
\end{tabular}

Agar lebih jelasnya hasil daya ledak otot tungkai atlet renang Kota Padang dapat dilihat pada gambar histogram dibawah ini :

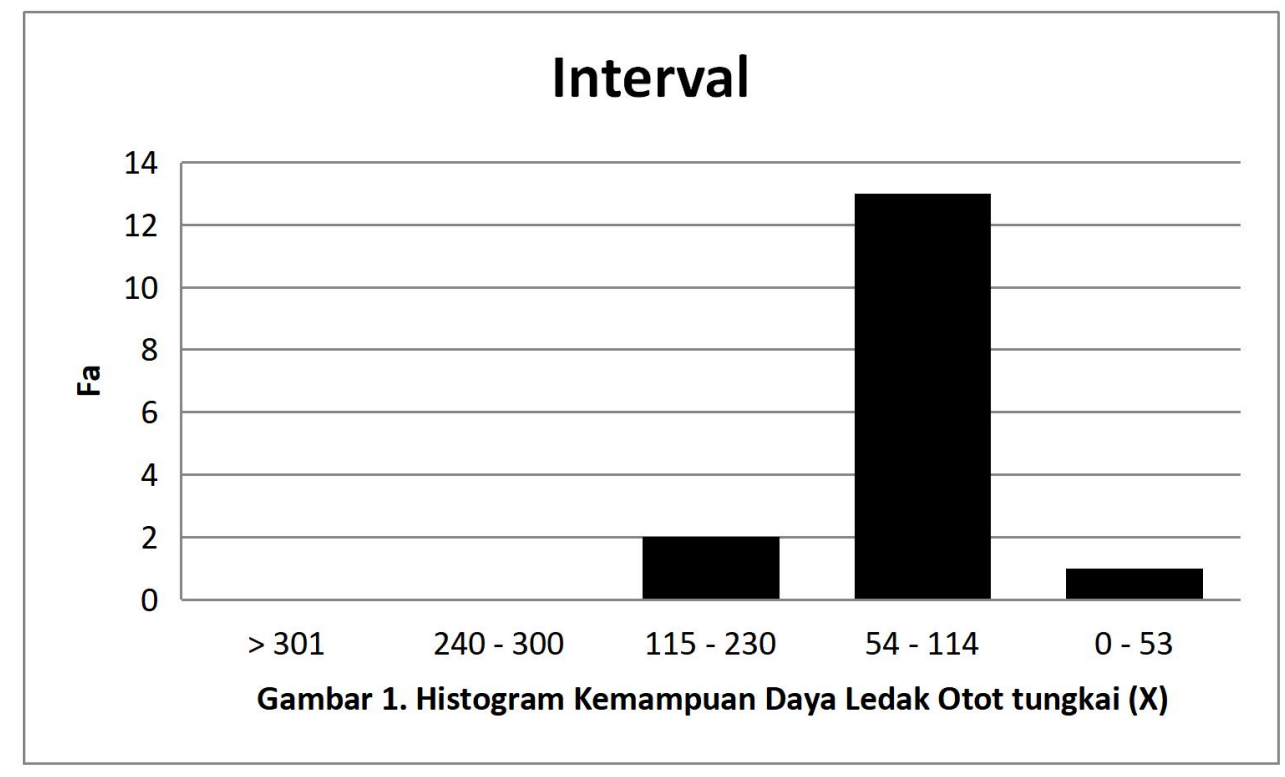

Berdasarkan tabel di atas dari 16 orang sampel, 2 orang (33.3\%) memiliki daya ledak otot tungkai 115-230 dengan kategori cukup, 13 orang (81.25\%) memiliki daya ledak otot tungkai 54-114 dengan kategori kurang dan 1 orang $(6.25 \%)$ memiliki daya ledak otot tungkai 0-53 dengan kategori kurang sekali.

\section{Kemampuan renang 50 meter gaya dada}

Dari hasil tes dan pengukuran kemampuan renang 50 meter daya dada dengan menggunakan tes kemampuan renang dengan hitungan waktu tercepat $35.54 \mathrm{dt}$ dan waktu terendah $59.86 \mathrm{dt}$, sedangkan nilai mean dalam pengukuran prestasi renang 50 meter gaya dada adalah 44.89 dengan standar deviasi 7.78. Dengan $\mathrm{n}=16$ orang dan taraf nyata $\alpha=0.05$ didapat $\mathrm{L}$ tabel $=0.213$ dan $\mathrm{Lo}=$ 
0.2014 , berarti Lo $<\mathrm{L}$ tabel, sehingga hipotesis nol diterima. Hal ini berarti data cendrung berdistribusi normal, untuk lebih jelasnya dapat dilihat pada lampiran.

\section{A. Analisis Data}

Sebelum melakukan pengujian hipotesis tentang daya ledak otot tungkai (X) terhadap kecepatan renang 50 meter gaya dada atlet renang Kota Padang (Y) terlebih dahulu dilakukan uji persyaratan analisis yaitu uji normalitas sebaran data. Setelah data diuji dengan persyaratan analisis dilakukan uji hipotesis.

\section{Uji normalitas sebaran data}

Hasil analisis sebaran data masing-masing variabel disajikan dalam tabel di bawah ini:

Tabel 6 : Rangkuman uji normalitas sebaran data dengan uji liliefors

\begin{tabular}{|l|l|l|l|l|l|}
\hline No & Variabel & $\mathbf{n}$ & Lo & Ltabel(0.05) & Distribusi \\
\hline 1 & Daya ledak otot tungkai (X) & 16 & 0.1832 & 0.213 & Normal \\
\hline 2 & $\begin{array}{l}\text { Kecepatan renang 50 meter } \\
\text { gaya dada (Y) }\end{array}$ & 16 & 0.2014 & 0.213 & Normal \\
\hline
\end{tabular}

Tabel di belakang menunjukkan bahwa hasil pengujian untuk daya ledak otot tungkai (x), skor Lo $=0.1832$ dengan $\mathrm{n}=16$, sedangkan Ltab pada taraf pengujian signifikan $\alpha=0.05$ diperoleh 0.213 ysng lebih besar dari Lo sehingga dapat disimpulkan bahwa skor yang diperoleh dari daya ledak otot tungkai berdistribusi normal. Agar lebih jelasnya dapat dapat dilihat pada lampiran.

Selanjutnya hasil tes kecepatan renang 50 meter gaya dada atlet renang Kota Padang (y), skor Lo $=0.2014$ dengan $\mathrm{n}=16$, sedangkan Ltab pada taraf pengujian signifikan $\alpha=0.05$ diperolah 0.213 yang lebih besar dari Lo sehingga dapat disimpulkan bahwa skor yang diperoleh dari kecepatan renang 50 meter gaya dada atlet renang Kota Padang berdistribusi normal. Agar lebih jelasnya dapat dilihat pada lampiran.

Berdasarkan uraian di atas ternyata variabel daya ledak otot tungkai (x) terhadap kecepatan renang 50 meter gaya dada atlet renang Kota Padang (y) datanya tersebar secara normal, karena masing-masing variabel skor Lo nya kecil dari pada Ltab pada taraf signifikan $\alpha=0.05$. Hal ini berarti bahwa data masing-masing variabel penelitian ini tersebar secara normal atau populasi dari mana data sampel diambil berdistribusi normal.

\section{Analisis korelasi dan kontribusi daya ledak otot tungkai $(\mathrm{X})$ terhadap kecepatan renang 50} meter gaya dada atlet renang Kota Padang (Y)

Adapun hasil analisis korelasi antara daya ledak otot tungkai (X) terhadap kecepatan renang 50 meter gaya dada atlet renang Kota Padang (Y) dengan menggunakan rumus korelasi sederhana (productmoment) sebagai berikut :

$$
\begin{gathered}
r_{o}=0,734 \\
r_{t a b}(\alpha=0,05)=0,497
\end{gathered}
$$

Ternyata $r_{o}>r_{t a b}$, akibatnya Ho ditolak (Ha diterima)

Selanjutnya diperoleh kontribusi dengan rumus kontribusi (korelasi secara simultan) sebagai berikut:

\section{Uji Hipotesis}

$$
\text { Kontribusi }=53,9 \%
$$

Berdasarkan hasil analisis korelasi dan kontribusi diperoleh $r_{o}(0,734)>r_{t a b}(0,497)$ pada taraf pengujian signifikan $\alpha=0,05$, artinya terdapat hubungan secara signifikan antara daya ledak otot tungkai terhadap kecepatan renang 50 meter gaya dada atlet renang Kota Padang. Selanjutnya diperoleh kontribusi $\left(r^{2}\right)=0,539>r_{t a b}=0,497$ pada taraf pengujian signifikan $\alpha=0,05$, artinya terdapat kontribusi secara signifikan antara daya ledak otot tungkai terhadap kecepatan renang 50 meter gaya dada atlet renang Kota Padang. 
Kemudian kontribusi dijadikan dalam bentuk presentase $=53,9 \%$, artinya daya ledak otot tungkai dapat memberikan kontribusi (sumbangan) secara signifikan terhadap kecepatan renang 50 meter gaya dada atlet renang Kota Padang sebesar 53,9\% oleh sebab itu hipotesis diterima.

Agar lebih jelasnya dapat dilihat pada tabel rangkuman analisis korelasi dan kontribusi daya ledak otot tungkai (X) terhadap kecepatan renang 50 meter gaya dada atlet renang Kota Padang (Y).

Tabel 7 : Rangkuman Analisis Korelasi dan Kontribusi Daya Ledak Otot Tungkai (X) Terhadap Kecepatan Renang 50 Meter Gaya Dada Atlet Renang Kota Padang (Y)

\begin{tabular}{|l|c|l|l|l|l|}
\hline $\mathbf{d k}(\mathbf{n}-1)$ & $\boldsymbol{r}_{\mathbf{0}}$ & $\boldsymbol{r}_{\boldsymbol{t a b}} \mathbf{0 , 0 5}$ & $\begin{array}{c}\boldsymbol{r}^{\mathbf{2}} \\
(\text { kontribusi) }\end{array}$ & $\begin{array}{l}\boldsymbol{r}^{\mathbf{2}} \mathbf{1 0 0 \%} \\
\mathbf{1 0 0}\end{array}$ & Kesimpulan \\
\hline 15 & 0,734 & 0,497 & 0,539 & $53,9 \%$ & Signifikan \\
\hline
\end{tabular}

Keterangan :

$\mathrm{dk}=$ derajat kebebasan

$\mathrm{n}=$ jumlah sampel

$r_{0}=$ tingkat hubungan

$r_{\text {tab }}=$ taraf pengujian signifikan

$r^{2}=$ kontribusi

$r^{2} \%=$ kontribusi dalam bentuk tingkat persentase

\section{Pembahasan}

Berdasarkan hasil analisa data terlihat daya ledak otot tungkai memberikan kontribusi yang berarti, dapat dilihat dari $r_{o}=0,734>r_{t a b}=0,497$. Ini menegaskan bahwa kemampuan renang 50 meter gaya dada tidak terlepas dari pengaruh daya ledak otot tungkai. Berdasarkan pengertian daya ledak otot tungkai itu sendiri merupakan kemampuan menampilkan kekuatan yang besar dalam waktu yang sangat cepat sehingga otot berkontraksi dengan kuat dan cepat. Oleh karena itu daya ledak otot tungkai yang bagus dapat menghasilkan lompatan dan luncuran yang jauh. Jadi, seandainya atlet renang Kota Padang memiliki daya ledak otot tungkai yang baik, maka prestasi renang khususnya renang 50 meter gaya dada akan lebih baik lagi.

Berdasarkan hal diatas, dapat kita sadari bahwa untuk mendapatkan prestasi renang 50 meter gaya dada tidak terlepas dari kondisi fisik khususnya daya ledak otot tungkai.

\section{KESIMPULAN}

Berdasarkan hasil penelitian dapat dikemukakan kesimpulan bahwa "Terdapat Kontribusi Antara Daya Ledak Otot Tungkai Terhadap Kecepatan Renang 50 Meter Gaya Dada Atlet Renang Kota Padang sebesar 53,9 \%”. berikut :

Berdasarkan pada kesimpulan di atas, maka penulis dapat memberikan saran-saran sebagai

1. Bagi pelatih disarankan untuk melatih unsur daya ledak otot tungkai dengan cara melatih otot-otot yang dominan dalam melakukan renang gaya dada, seperti latihan Plyometri,

2. Bagi atlet agar melakukan latihan dengan sungguh-sungguh dan berkesinambungan.

3. Bagi peneliti yang ingin melanjutkan penelitian ini agar dapat meneliti dengan jumlah populasi dan sampel yang lebih banyak lagi.

\section{DAFTAR RUJUKAN}

Arsil. 1999. Pembinaan Kondisi Fisik. Padang : FIK UNP 
Depdikbud. 1982. Cara Belajar dan Mengajar Renang. Proyek Pembinaan Permasalahan dan Pembibitan Olahraga Renang.

Don R. Kirkendall, Measurement and Evaluation for Physical Educationditerjemahkan oleh ME. Winarno, dkk. (Jakarta : ASWIN, 1997), h. 240.

Harsono, Loc. Cit, (Jakarta : P2LPTK, 1980), h. 200.

Jalmaidi. 1993. Hubungan antara Power dan Kelincahan dengan Keterampilan Bermain Bulutangkis Tingkat Dasar Mahasiswa FPOK IKIP Padang. Padang :FPOK IKIP.

Lutan, Rusli dkk. 1991. Manusia dan Olahraga. Bandung : ITB dan FPOK IKIP Bandung.

Maidarman. 2004. Pengajaran Renang :Program Hibah Kompetisi A - I 2004. Padang : FIK UNP

Marzuki, Chalid. 1999. Renang Dasar. Padang : FIK UNP

Maglischo, Ernest W. 1993. Swimming Even Faster. California : California State University

Pate, Russell R dkk. 1993. Dasar-dasar Ilmiah Kepelatihan. New York.University of South Carolina.

Sajoto, Moch. 1988. Pembinaan Kondisi Fisik Dalam Olahraga, Jakarta, Depdikbud.

Soeharno . 1986. Ilmu Pelaihan Olahraga. Yogyakarta : FPOK-IKIP

Soejoko, Hendromartono. 1992. Olahraga Pilihan Renang. Jakarta : Depdikbud

Soekarman. 1987. Dasar-dasar Olahraga Untuk Pembina, Pelatih dan Atlet. Jakarta : Haji Masagung

Sudjana, Nana. 1992. Metode Statistik. Bandung : Tarsita

Syafruddin. 1996. Pengantar Ilmu Melatih. Padang :FPOK IKIP

Syafruddin. 1999. Dasar-dasar Kepelatihan Olahraga. Padang : FIK UNP

Umar, Husen. 1998. Metode Penelitian Untuk Skripsi dan Tesis Bisnis. Jakarta : Raja Grafindo Persada.

Undang-Undang RI No.3 (2005). Tentang Sistem Keolahragaan Nasional

Winarno. 1990. PengantarPenelitianIlmiah. Bandung : Tarsito

Yusuf, A. Muri. 2007. Metodologi Penelitian :Dasar-dasar Penyelidikan Ilmiah. Padang : UNP 